\title{
Pondok literasi berbasis kearifan lokal sebagai media pembelajaran di SD Negeri 024 Banjar XII, Tanah Putih, Rokan Hilir, Riau
}

\author{
Wendi Silitonga, Sandewa Jopanda, Ayu Syafitri, Putriany Yoranda, dan Mita Rosaliza* \\ Universitas Riau \\ * mita.rosaliza@ lecturer.unri.ac.id
}

\begin{abstract}
Abstrak. Perpustakaan merupakan salah satu sarana belajar yang cukup penting dalam institusi pendidikan. Di zaman era global seperti sekarang, bahkan TK dan PAUD wajib memiliki perpustakaan sebagai wujud upaya pemerintah mencerdaskan kehidupan bangsa. Ketidakberadaan perpustakaan, menjadi satu dari beberapa factor rendahnya minat baca.Tulisan ini membahas Pondok literasi sebagai media belajar di SDN 024 Menggala Jounction, Banjar XII, Kecamatan Tanah Putih, Kabupaten Rokan Hilir. Beberapa metode yang penulis lakukan ialah membangun pondok literasi (RAMBU POLISI), membukadonasi buku dan sebagainya (SIM B), program senandung kisah literasi yang dilakukan dengan monolog (SEKILAS), belajar tentang karakter (BETTER), pembelajaran ceria dan kreatif (CERIBEL), dan terakhir program reading book culture yang penulis sebut RIAU (reading is a culture). Tulisan ini memberikan sebuah penjelasan sosiologis mengenai fungsi pondok dan menganalisis pendapat masyarakat umumnya dan warga sekolah khususnya untuk mengetahui respons dan dampak dari adanya pondok tersebut.Pondok merupakan salah satu budaya kearifan negeri yang tersebar di berbagai nusantara yang biasanya digunakan sebagai tempat berkumpul atau bermain. Dari studi kasus di Desa Menggala Jounction yang dilaksanakan pada bulan April-Juni 2019 lalu, penulis menemukan bahwa hegemoni teknologi masa kini belum masuk pada masyarakat Menggala Jounction. Pondok literasi yang berbasis local wisdom masih mampu menarik minat baca dan tulis.
\end{abstract}

Kata kunci: literasi; Perpustakaan; Rokan Hilir

Abstract. The library is one of the important learning facilities in educational institutions. In the era of the global era like now, even TK and PAUD must have a library as a manifestation of the government's efforts to educate the life of the nation. The absence of libraries is one of the few factors in the low interest in reading. This paper discusses the Literacy Board as a learning media at 024 Menggala Jounction SDN, Banjar XII, Tanah Putih District, Rokan Hilir Regency. Some of the methods that I do are building literacy huts (POLICE POLICE), opening book donations and so on (SIM B), programs containing stories of literacy carried out by monologue (GLANCE), learning about character (BETTER), cheerful and creative learning (CERIBEL), and finally the reading book culture program that I call RIAU (reading is a culture). This paper provides a sociological explanation of the function of the lodge and analyzes the opinions of the general public and school members especially to find out the response and impact of the existence of the hut. The lodge is one of the cultures of the country's wisdom that is spread across various archipelago which is usually used as a gathering place or playground. From the case study in Menggala Jounction Village which was held in AprilJune 2019, the author found that today's technological hegemony has not yet entered the community of Menggala Jounction. Literacy huts based on local wisdom are still able to attract reading and writing interest.

Keywords: literacy; library; Rokan Hilir

To cite this article: Silitonga, W., S. Jopanda, A. Syafitri, P. Yoranda, \& M. Rosaliza. 2019. Pondok literasi berbasis kearifan lokal sebagai media pembelajaran di SD Negeri 024 Banjar XII, Tanah Putih, Rokan Hilir, Riau. Unri

Conference Series: Community Engagement 1: 388-393 https://doi.org/10.31258/unricsce.1.388-393

(C) 2019 Authors

Peer-review under responsibility of the organizing committee of Seminar Nasional Pemberdayaan Masyarakat 2019 


\section{PENDAHULUAN}

"Pendidikan adalah senjata paling ampuh untuk mengubah dunia," itulah ucapan seorang Nelson Mandela. Secara sederhana, kalimat tersebut menyimpulkan bahwa pendidikan memiliki dampak besar terhadap perkembangan peradaban manusia dimuka bumi. Orang pertama yang dicari setelah bom atom jatuh di Hiroshima dan Nagasaki pada 6 dan 9 Agustus, adalah para guru dan tenaga pendidik. Hal tersebut menandai bahwa untuk membangun bangsa, pendidikan adalah hal yang utama. Timbulah ungkapan, "pendidikan adalah tonggak sebuah bangsa".

Menurut UU No. 20 tahun 2003, tentang Sistem Pendidikan Nasional pasal 1 ayat 1 (Idi, 2011), pendidikan adalah suatu usaha sadar dan terencana untuk mewujudkan suasana belajar dan proses pembelajaran agar peserta didik secara aktif mengembangkan potensi dirinya untuk memiliki kekuatan spiritual, keagamaan, pengendalian diri, kepribadian, kecerdasan, akhlak mulia serta keterampilan yang diperlukan dirinya, masyarakat,bangsa dan negara.

Pada umumnya, bentuk pendidikan formal yang berjalan di Indonesia terdiri dari tiga jenjang(UU RI No. 20 Tahun 2003 Pasal 14) yaitu, pendidikan dasar (SD/MI), pendidikan menengah (SLTP/MTS, dan SLTA/MA), dan pen-didikan tinggi.

Menurut KBBI (Depdiknas, 2008), sekolah adalah bangunan atau lembaga untuk belajar dan mengajar serta tempat menerima dan memberi pelajaran. Di sekolah seorang pendidik sedapat mungkin dapat memahami dan mendorong proses sosialisasi peserta didik seoptimal mungkin dengan berbagai latar belakang sosial peserta didik. Prinsipnya, bahwa proses sosialisasi peserta didik membutuh-kan perhatian lebih dibidang infrastruktur sekolah.

Terkait infrastruktur sekolah, menurut hasil survei international institute for management development (IMD) (Prasetyo, 2018), menunjukkan Indonesia di peringkat 43 dari 63 negara dengan titik lemah tingkat daya saing Indonesia salah satunya terletak pada aspek infrastruktur yang meliputi infrastruktur sains dan infrastruktur pendidikan. Jelas merupakan PR bagi pemerintah untuk memper-baiki infrastruktur pendidikan agar bisa menjadikan Indonesia bangsa yang berkualitas. Keterlibatan pemerintah dalam wilayah pendidikan juga tidak harus dominan (sentralistis), pada pembangunan non-fisik semata-mata, tapi perlu kemudian dilakukan perimbangan pembangunan fisik dan non-fisik.

Tujuan dilaksanakannya program POLISI LALU LINTAS (Pondok Literasi Langkah Awal Untuk Lingkungan Berkualitas) adalah untuk menumbuhkan serta meningkatkan minat baca siswa-siswi di SD Negeri 024 Manggala Jounction Kel. Banjar XII, Kec. Tanah Putih, Kab. Rokan Hilir. Selain itu juga untuk menghidupkan kembali budaya lama yang telah tergerus zaman dengan mendirikan pondok sebagai tempat menbaca, menulis, bermain dan lainnya. Pemilihan pondok dikarenakan salah satu bentuk kearifan lokal dan juga sebagai inovasi sekaligus daya tarik bagi anak-anak/siswa-siswi.

\section{MASALAH}

UU RI No. 20 Tahun 2003 Tentang Sistem Pendidikan Nasional pasal 45 ayat 1 mengatakan setiap satuan pendidikan formal dan non formal menyediakan sarana dan prasarana yang memenuhi keperluan pendidikan sesuai dengan pertumbuhan dan perkembangan potensi fisik, kecerdasan intelektual, sosial, emosional, dan kejiwaan peserta didik. Infrastruktur pendidikan khususnya perpustakaan yang menjadi penunjang belajar siswa/i, wajib adanya di setiap sekolah di seluruh Indonesia. Namun perpustakaan yang sebenarnya adalah sarana belajar, tidak terlihat di SD Negeri 024 Menggala Jounction Kel. Banjar Xll. Hal ini menyebabkan siswa/i di SD tersebut tidak dapat membaca buku selain Lembar Kerja Siswa (LKS) yang dianjurkan para guru untuk dibeli.

Membaca bukan hanya menambah wawasan dan pengetahuan seseorang. Namun, juga dapat meningkatkan potensi diri. Menurut data UNESCO, minat baca masyarakat Indonesia sangat memprihatinkan hanya 0,001 persen artinya dari 1000 orang Indonesia hanya 1 orang yang rajin membaca (Indra, 2017.

Rendahnya minat baca di Indonesia memiliki beberapa faktor. Fasilitas baca yang kadang tidak dimiliki atau memadai merupakan salah satu penyebabnya. Padahal SD Negeri ini sudah mengalami dua kali penggantian nama namun tidak sekalipun dilakukan, pembenahan sarana dan prasarana. Sementara sarana dan prasarana harusnya dipenuhi demi terciptanya kualitas pendidikan yang inginkan. Peningkatan kualitas pendidikan secara sosial, haruslah dengan people centered development atau manusia sebagai pusat perencanaan (Hidir, 2009). Oleh sebab itu, diperlukan cara terbaik dan termudah yang sesuai dengan budaya masyarakat untuk menumbuhkan dan meningkatkan serta membudayakan baca tulis (literasi) sejak dini. Salah satunya ialah dengan pondok. Sebab masyarakat Indonesia umumnya dan Menggala Jounction khususnya 
sejak dahulu mengenal pondok sebagai media berkumpul, bincang, bermain bagi anak-anak dan lain sebagainya.

Berdasarkan uraian diatas, maka kami memiliki program POLISI LALU LINTAS (Pondok Literasi: Langkah Awal Untuk Lingkungam Berkualitas) agar meningkatkan minat baca siswa-siswi di SD Negeri 024 Menggala Jounction Kel. Banjar X11, Kec. Tanah Putih, Kab. Rokan Hilir. Beberapa program kegiatan yang direncanakan meliputi RAMBU POLISI (Rancang dan Membangun Pondok Literasi.SIM B untuk POLISI (Sumbangan Ilmu Melalui Buku Untuk Pondok Literasi. BETTER (Belajar Tentang Karakter), SEKILAS (Senandung Kisah Literasi Anak Sekolah), CERIBEL (Ceria Belajar), dan RIAU (Reading Is A Culture). Diharapkan dengan terlaksananya program ini, siswa-siswi SD Negeri 024 Menggala Jounction Kel. Banjar Xll dapat menambah wawasan dan terus membudayakan baca tulis untuk memajukan Indonesia dari segi literasi.

\section{METODE PELAKSANAAN}

Adapun teknik dan cara pelaksanaan dari program POLISI LALU LINTAS adalah mempersiapkan pelaksanaan program serta membuat perlengkapan dan peralatan penunjang program POLISI LALU LINTAS dan Pre-Test dengan memberikan kuesioner pre-test kepada siswa-siswi, guru, dan wali murid, sebelum pelaksanaan program. Kemudian tim POLISI LALU LINTAS akan kembali memberikan kuesioner kepada siswa-siswi, guru, dan wali murid, untuk mengukur perbandingan sebelum dan setelah program POLISI LALU LINTAS ini dilaksanakan. Setelah itu Tim POLISI LALU LINTAS akan mengadakan evaluasi untuk mengetahui kesesuaian pelaksanaan program dengan rencana yang telah ditetapkan diawal. Selain itu, evaluasi ini juga bertujuan untuk melihat program mana yang paling efektif untuk meningkatkan literasi siswa/i.

\section{Pelaksanaan Program}

SIM B untuk POLISI atau Sumbangan Ilmu Melalui Buku untuk pondok literasi.Kegiatan ini dilakukan di Pekanbaru, ibukota provinsi Riau tempat Tim menimbai lmu. Kemudian hasil pengumpulan buku tersebut akan langsung di seleksi sesuai dengan umur dan kelas siswa.

RAMBU POLISI (Rancang dan Membangun Pondok Literasi) Kegiatan men-dirikan pondok literasi yang bekerja sama dengan pihak sekolah, masyarakat dan perangkat desa. Penulis juga akan mengajak para pemuda ikut gotong royong membangun pondok tersebut. Selain itu akan di lakukan penataan dan pendekorasian POLISI sehingga terlihat menarik bagi para siswa/i SD Negeri 024 Menggala Jounction.

BETTER (Belajar Tentang Karakter) Tim akan mengawali kegiatan menanamkan moral dan akhlak mulia sehingga menjadi karakter yang melekat di jiwa anak bangsa, yang dalam hal ini adalah siswa/i SD Negeri 024 Menggala Jounction.

SEKILAS (Senandung Kisah Literasi Anak Sekolah) Di program ini, penulis dan akan melakukan monolog atau bercerita tentang kisah yang bermakna dan mampu memotivasi diri peserta didik. Kisah-kisah yang akan dinarasikan merupakan kisah yang memiliki unsur inspirasi, nasionalisme, sikap terpuji dan sebagainya.

CERIBEL (Ceria Belajar) Kegiatan di mana pembelajaran itu sendiri diikuti dengan permainan kecil yang interaktif, komunikatif, dan positif sehingga menghilang-kan rasa jenuh serta persepsi buruksiswa/i SD Negeri 024 Menggala Jounction bahwa belajar tidak menyenangkan kegiatan.

RIAU (Reading Is A Culture) Setelah semua kegiatan berlangsung maka terakhir adalah program pamungkas yaitu RIAU.Tujuannya untuk terus membudayakan baca dan tulis di kalangansiswa/i SD Negeri 024 Menggala Jounction.

\section{PEMBAHASAN}

\section{Melestarikan Kearifan Lokal dan Permainan Tradisional}

Ketidaktersediaan fasilitas baca merupakan salah satu faktor rendahnya minat baca. Kenyataan itu terlihat di SD Negeri 024 Banjar XII. Padahal SD Negeri ini sudah mengalami dua kali penggantian nama namun tidak sekalipun dilakukan, pembenahan sarana dan prasarana. Sementara sarana dan prasarana harusnya dipenuhi demi terciptanya kualitas pendidikan yang inginkan.

Peningkatan kualitas pendidikan secara sosial, haruslah dengan people centered development atau manusia sebagai pusat perencanaan (Hidir, 2009). Oleh sebab itu, diperlukan cara terbaik dan termudah yang sesuai dengan budaya masyarakat untuk menumbuhkan dan meningkatkan serta membudayakan baca tulis (literasi) sejak dini. Salah satunya ialah dengan pondok. Sebab masyarakat Indonesia umumnya dan Menggala 
Jounction khususnya sejak dahulu mengenal pondok sebagai media berkumpul, bincang, bermain bagi anakanak dan lain sebagainya.

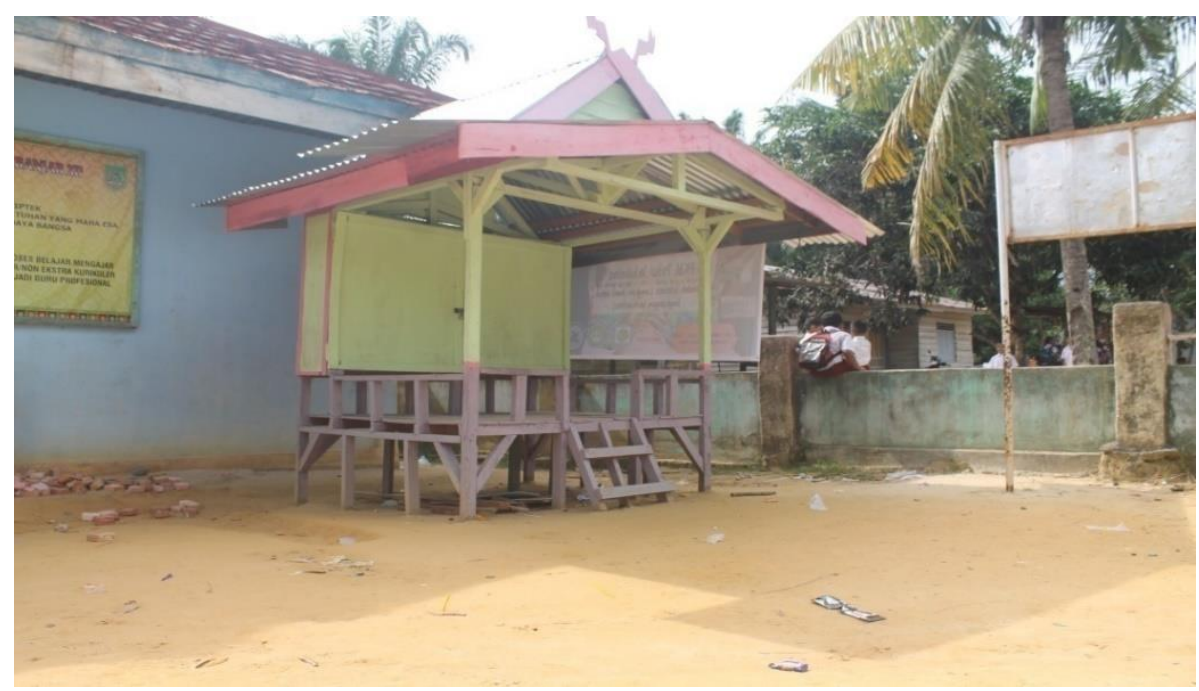

Gambar 1. Pondok Literasi

Pondok bukan hanya dikenal dalam masyarakat Melayu. Di Aceh atau Sumatera Barat, menyebut pondok dengan Gubuk. Pada masyarakat Sunda, kebanyakan mengenal nya dengan sebutan sawung. Sebagian orang didaerah jawa mengenalnya dengan cakrug.

Seperti yang telah dijelaskan, dalam perencanaan pembangunan, dari kacamata sosiologi, pengembangan pendidikan haruslah menjadikan manusia sebagai pusatnya. Sederhananya, pembangunan harus menyesuaikan kebutuhan manusia sehingga tepat sasaran dan dapat dimanfaatkan masyarakat. Tidak hanya bagunan fisik, melainkan juga dalam hal non fisik. Pondok literasi memang menarik bagi siswa/i, namun penulis pun menekankan kegiatan yang juga dekat dengan siswa/i dan masyarakat setempat.

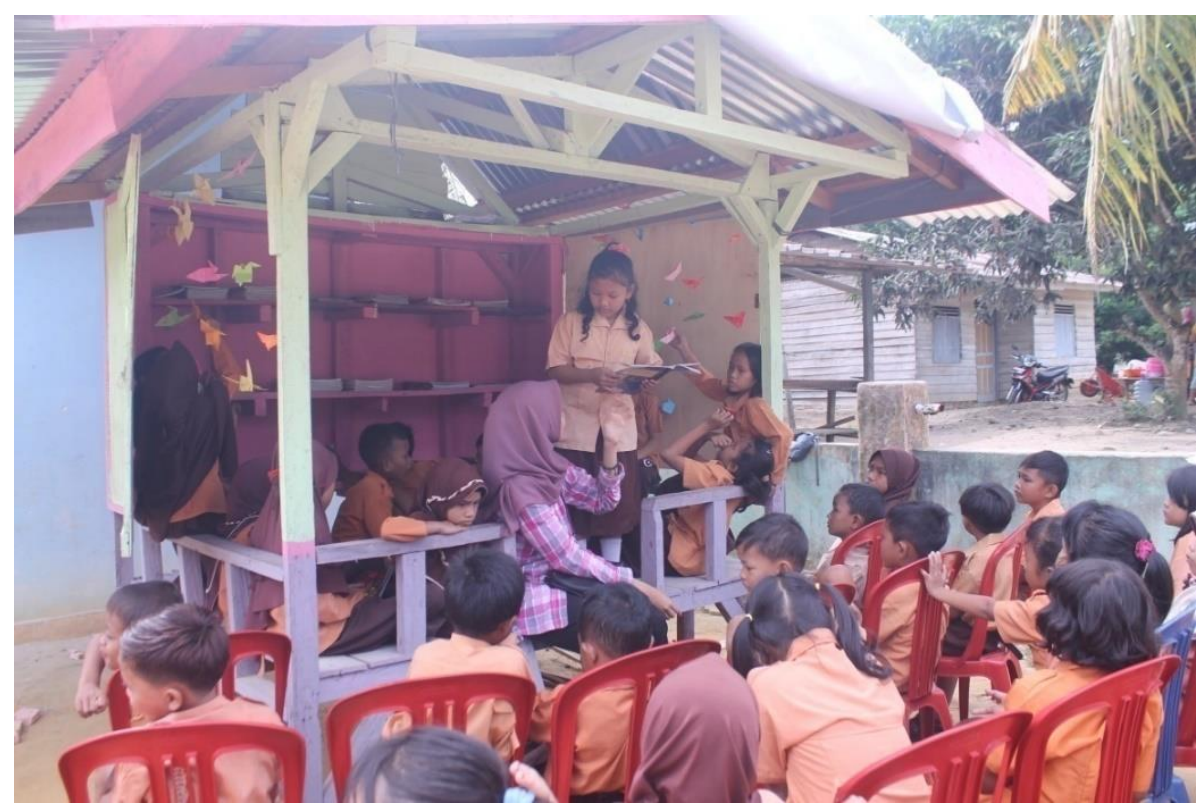

Gambar 2. Kegiatan di pondok literasi

Permainan tradisional atau nuansa kebudayaan dipadukan dengan kegiatan yang dirancang oleh penulis. Seperti cerita rakyat yang dibiasakan untuk diceritakan pada saat monolog (Sekilas). Tokoh adat melayu, atau tokoh nasional berdarah melayu yang berhasil atau sukses menjadi tauladan utama di dalam kegiatan seperti 
Better (belajar tentang karakter). Permainan lumbung atau congkak pun ikut dijadikan bahan utama saat kegiatan Ceribel (ceria belajar).

\section{HASIL}

Setiap pengabdian masyarakat tentunya diharapkan memiliki luaran yang berguna kepada sasaran. Luaran yang diharapkan dapat tercapai ialah dibidang jasa, barang, tulisan, dan desain. Luaran tersebut sejatinya tidak menghapuskan esensi utama yakni peningkatan minat baca. Adapun luaran dari sebuah pengabdian masyarakat merupakan pendukung agar terciptanya suatu pemberyaaan yang memadai.

Terlihat bahwa di awal program masihsedikitsiswa/i yang dating ke pondok literasi. Namun pada program CERIBEL jumlah siswa/i SD Negeri 024 Banjar XII mengalami peningkatan. Meskipun sedikit, tetapi hingga program Riau, Statistik menunjukkan peningkatan pengunjung. Memang pada tanggal 24 April, hanya 17 orang yang datang lalu, naik satu orang di hari berikutnya. Pada 16 Mei jumlah pengunjung naik sekitar $80 \%$ dari jumlah pengunjung.

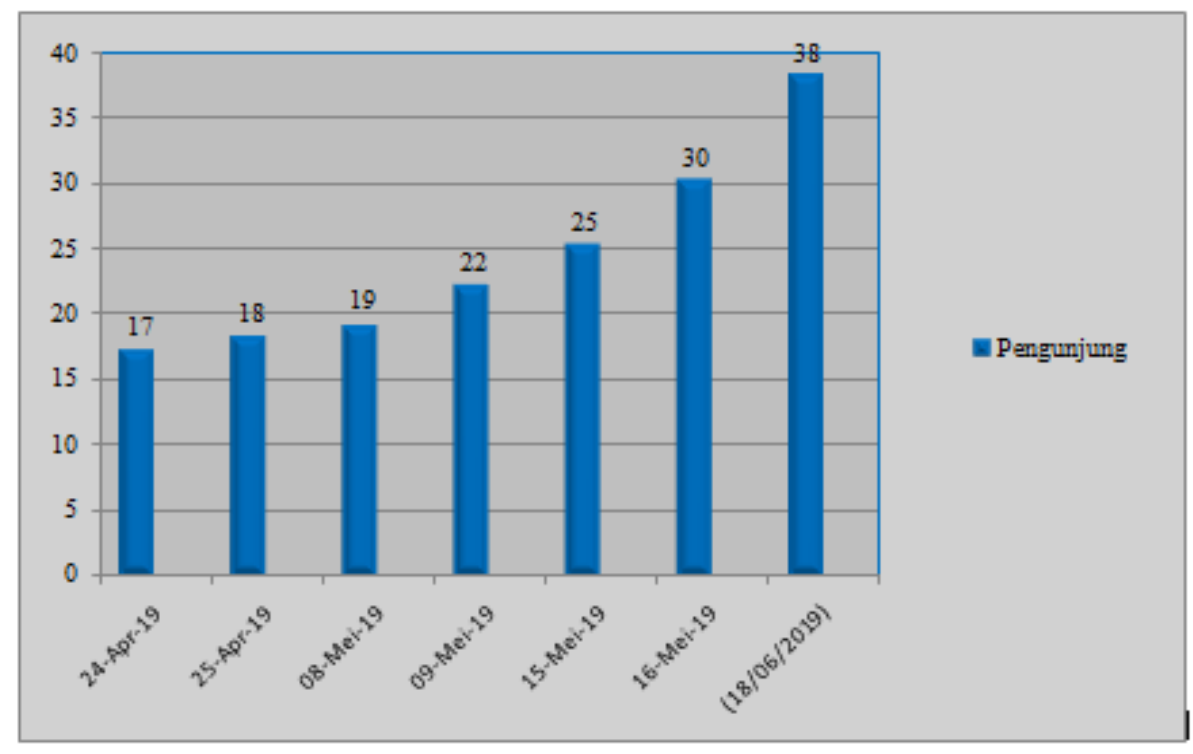

Gambar 3. Diagram Jumlah Pengunjung

Berdasarkan diagram tersebut dari awal program hingga akhir didapati peningkatan yang cukup lumayan. Meskipun sedikit, tetapi konsisten sehingga terlihat stabil. Persentase kenaikan setiap harinya ialah 1,51\% persen. Jika di cari perbandingan akhir dan awal, maka didapati 9,85\% s. Jika program ini dilakukan dalam dua bulan maka persentase pengunjung bisa mencapai $100 \%$.

\section{KESIMPULAN}

Pondok literasi merupakan gagasan yang solutif dari permasalahan ketidakberadaan perpustakaan di sekolahsekolah di Indonesia. Pengambilan pondok sebagai respon tidak adanya fasilitas baca bukan semata-mata demi kemudahan penulis melaksanakan kegiatan. Tetapi juga melestarikan kearifan lokal.

Pada masa yang serba digital ini, library app memang bertebaran di internet. Ada banyak jasa penyedia layanan referensi tetapi hal tersebut akan sukar sekali diakses bila tidak memilki gawai. Kebanyakan orang Indonesia juga mengerti akan hal ini.

Keberadaan pondok di SD Negeri 024 mampu meningkatkan minat baca merupakan bukti bahwa kecanggihan teknologi yang mengglobal belum sampai menyelimuti seluruh dunia. Banyak daerah terpencil dan masih banyak tempat yang memegang tradisinya dengan erat. Ini juga bukan berarti Pondok Literasi menghalangi atau ingin melawan perkembangan saat ini. Akan tetapi, mencoba memberi jalan keluar dari perubahan yang diinginkan dalam sebuah lingkungan pendidikan. 


\section{DAFTAR PUSTAKA}

Bungin, Burhan. 2006. Sosiologi Komunikasi: Teori, Paradigma, dan Diskursus Teknologi Komunikasi di Masyarakat. Jakarta: Kencana Prenada Media.

Departemen Pendidikan Nasional.2008. Kamus Besar Bahasa Indonesia. Jakarta: Balai Pustaka.

Hidir, Achmad. 2009. Antropologi Budaya; Perspektif Ekologi dan Perubahan Budaya. Pekanbaru: Unri Press.

Idi, Abdullah. 2011. Sosiologi Pendidikan: Individu, Masyarakat, dan Pendidikan. Jakarta: Rajawali Pers.

Indra, Rahman. 2017. Memaknai Buku dan Minat Baca di Hari Buku Nasional 2017. (https://m.cnnindonesia.com/gayahidup//20170517114249-277-215422/memaknai-buku-dan-minat-baca-di-hari-buku-nasional-2017.html Diakses tanggal 8 Januari 2019 pukul 19.30 WIB).

Prasetyo, W. B. 2018. IMD World Competitiveness 2018, Peringkat RI Turun Jadi 43.

https://www.beritasatu.com/ekonomi/495733-imd-world-competitiveness-2018-peringkat-ri-turun-jadi-43.html Diakses tanggal 8 Januari 2019 pukul 22.40 WIB).

Undang-Undang Republik Indonesia Nomor 20 Tahun 2003 Tentang Sistem Pendidikan Nasional. 